\title{
Transcranial Magnetic Stimulation and Antidepressive Drugs Share Similar Cellular Effects in Rat Hippocampus
}

\author{
Y. Levkovitz, M.D., N. Grisaru M.D., and M. Segal Ph.D.
}

Transcranial magnetic stimulation (TMS) has been proposed as a safe and efficient treatment of human clinical depression. Although its antidepressive mechanism of action remained unknown, our previous studies indicate that TMS has a long-lasting effect on neuronal excitability in the hippocampus. We now compare the effects of chronic TMS with those of the antidepressant drugs desipramine and mianserin. The three treatments did not affect basal conduction in the perforant path to the dentate gyrus, but markedly suppressed paired-pulse and frequency-dependent inhibition, resulting from a reduction in local circuit inhibition in the dentate gyrus. Concomitantly, these treatments enhanced the expression of long-term potentiation in the perforant path synapse in the dentate gyrus. Finally, chronic TMS as well as mianserin suppressed the serotonin-dependent, potentiating action of fenfluramine on population spike in the dentate gyrus. Thus, TMS, mianserin, and desipramine are likely to affect the same neuronal populations, which may be relevant to their antidepressant action.

[Neuropsychopharmacology 25:608-616, 2001] (C) 2001 American College of Neuropsychopharmacology. Published by Elsevier Science Inc.
KEY WORDS: TMS; Mianserin; Desipramine; Depression; Dentate gyrus

With a prevalence of at least 4 to $6 \%$ in the general population, clinical depression is the most common of all psychiatric disorders. Although its pathophysiology is not fully understood, there is growing evidence supporting a major involvement of the hippocampus in cognitive aspects of depressive disorders. Depression is associated with hippocampal atrophy (Krishnan et al. 1991; Sheline 1996; Sheline et al. 1996). This volume loss is related to memory function and significantly correlates with total lifetime duration of depression (Shah et al. 1998; Sheline et al. 1999). Classic antidepressant

From the Department of Neurobiology, The Weizmann Institute, Rehovot, Israel.

Address correspondence to: M. Segal, Department of Neurobiology, The Weizmann Institute, Rehovot 76100, Israel. Tel: 972-89-342553; Fax: 972-89 -344-140; E-mail: menahem.segal@weizmann.ac.il

Received 24 July 2000; revised 18 October 2000; accepted 27 November 2000. treatments, tricyclic antidepressants (TCA), and electroconvulsive shock (ECS) lead to changes in morphology and survival of hippocampal neurons (Vaidya et al. 1999). The hippocampus is innervated by serotonergic and noradrenergic fibers, both affected by depression. Thus, the hippocampus is an attractive target for the analysis of the effects of antidepressive treatments on brain physiology.

Transcranial magnetic stimulation (TMS) is a new noninvasive, fairly safe method for stimulation of the brain (Barker 1991). Magnetic stimulation of the human brain is increasingly used for functional cortical mapping of primary motor pathways and speech areas and for the investigation of cortical functions related to cognition in both health and disease states (Barker et al. 1986; Hallett and Cohen 1989; Gates 1995). TMS has been suggested recently for the treatment of psychiatric disorders of mood and emotional dysfunctions (Hoflich et al. 1993; Grisaru et al. 1994; George et al. 1995; Klein et al. 1999). 
In an earlier study, we found long-lasting effects of TMS on reactivity of the hippocampus to stimulation of its main excitatory afferent pathway arising from the entorhinal cortex, the perforant path (Levkovitz et al. 1999). Chronic TMS did not affect single population spikes but caused an increase in paired-pulse facilitation, which was still evident 3 weeks after the last of a series of TMS treatments. Serotonergic and noradrenergic modulation of evoked synaptic activity may be related to these long-term TMS effects on synaptic transmission.

Surprisingly, little is known about chronic effects of antidepressant treatments on synaptic activity in the hippocampus of the intact rat (Haddjeri et al. 1998). The objectives of the present study are to characterize and compare long-term effects of TMS and two antidepressant drugs, desipramine (selective norepinephrine reuptake blocker) and mianserin (selective 5-HT2 serotonin receptor antagonist, and a partial alpha-2 adrenergic receptor antagonist) on evoked synaptic activity in the hippocampus.

\section{MATERIALS AND METHODS}

\section{Recording}

Experiments were conducted with adult (3-4 month old) male Long-Evans rats as detailed elsewhere (Levkovitz and Segal 1997). The rats were housed in a temperature-controlled room, 3 to 4 per cage, with $12 \mathrm{~h}$ light/dark cycle and free access to food and water.

Five groups were compared: (1) TMS $(n=6)$; (2) TMS controls; (3) desipramine $(n=5 ; 10 \mathrm{mg} / \mathrm{kg} /$ day, IP) for 7 days; (4) mianserin $(n=5,5 \mathrm{mg} / \mathrm{kg} /$ day, IP) for 7 days; and (5) drug control, treated with saline $(0.9 \% /$ day) for 7 days. The results of the two control groups were similar and were, therefore, pooled.

\section{TMS}

One millisecond pulses were applied with a Cadwell (Kennewick, WA) Rapid Stimulator at a frequency of 25 $\mathrm{Hz}$ for 2 seconds with a maximal field intensity of 2.2 tesla; flowing clockwise; calculated between 1-1.5 cm from the center of the coil (Cohen et al. 1990). Estimated peak electric field strength was $660 \mathrm{~V} / \mathrm{m}$ through $5-\mathrm{cm}$ coil with a teardrop shape. The coil was placed above the head, aligned with its center on the midline, equidistant between the bregma and lambda sutures along the longitudinal body axis. Using these stimulation parameters, the hippocampus and posterior cortex are likely to be stimulated irrespective of the skull (Cohen et al. 1990). Awake rats were stimulated once daily for 7 day. Control rats were held the same way as the treated ones and were exposed to the same noise produced during the stimulation.
Starting one day after the last treatment, rats were anesthetized with urethane $(1.2 \mathrm{gm} / \mathrm{kg}, \mathrm{IP})$ and placed in a stereotaxic instrument. A bipolar, $125 \mu \mathrm{m}$ concentric stimulating electrode was placed in the perforant path (PP) (coordinates: $7.5 \mathrm{~mm}$ posterior to bregma, 4.0 $\mathrm{mm}$ lateral to the midline, depth of $3.5 \mathrm{~mm}$ ), and a glass pipette $(2 \mu \mathrm{m}$ tip diameter) containing $2 \mathrm{M} \mathrm{NaCl}$ was moved into the dentate gyrus of the dorsal hippocampus (coordinates $4.0 \mathrm{~mm}$ from bregma, $3.0 \mathrm{~mm}$ lateral to midline, at a depth of 3-4 $\mathrm{mm}$ ) using an hydraulic microdrive. Electrode positions were optimized to record maximal population spike (PS) in response to $100 \mu$ s pulse stimulation of the medial PP. Evoked responses were amplified and filtered at $1 \mathrm{~Hz}$ to $1 \mathrm{kHz}$ and stored for later analysis.

The following electrophysiological measurements were made in all the rats, in the same sequence. Care was taken to allow recovery from each test before the next one.

\section{Paired-Pulse Inhibition}

A twin pulse PP stimulus was delivered at three interpulse intervals $(15,30$ and $60 \mathrm{~ms})$, and averages of five successive responses to a given intensity applied at a rate of $0.5 \mathrm{~Hz}$ were constructed. Paired-pulse response was quantified as the magnitude of the second over the first PS or the slope of the second EPSP over the first one.

\section{Frequency-Dependent Inhibition}

Two series of stimuli were delivered, each one contained 20 stimuli at $1 \mathrm{~Hz}$ and 20 stimuli at $0.1 \mathrm{~Hz}$, with baseline recorded between the two series. PS and EPSP measured as the average of 40 stimuli at the same frequency relative to prior baseline condition. Differences in PS and EPSP between the two frequencies were quantified as the second minus the first PS (PS $0.1 \mathrm{~Hz}-$ PS $1 \mathrm{~Hz}$ ) or the EPSP slope of the second minus the first slope (EPSP $0.1 \mathrm{~Hz}-$ EPSP $1 \mathrm{~Hz}$ ).

\section{LTP Induction}

After electrode insertion, input-output relations, paired-pulse stimulation and frequency-dependent inhibition were obtained, recording was made for $15 \mathrm{~min}$ followed by $10 \mathrm{~min}$ of baseline, pretetanus recording. The LTP-inducing stimulation intensity was at $50 \%$ of the level that evoked maximum asymptotic spike amplitude. LTP was induced with 10 trains of eight $0.4 \mathrm{~ms}$ $400 \mathrm{~Hz}$ pulses with an intertrain interval of $1 \mathrm{~s}$. LTP in each experiment was assessed as the change in the response measured 35 to $40 \mathrm{~min}$ after tetanus, and expressed as a percentage of the mean of the 20 responses obtained within $10 \mathrm{~min}$ before the tetanus. 


\section{Serotonergic Modulation}

Seventy minutes after the tetanic stimulation, serotonergic modulation of PS was measured using the serotonin releaser, fenfluramine (FFA, $7.5 \mathrm{mg} / \mathrm{kg}$, IP). PS and EPSP were measured 15 and 25 min after FFA.

\section{Analysis}

Off-line measurements of the slopes of the EPSPs (in volts per second) and magnitudes of the maximal population spike (in millivolts) were made from averages of five successive responses to a given stimulation intensity applied at a rate of $0.1 \mathrm{~Hz}$. PS size and EPSP slope were measured as described previously (RichterLevin and Segal 1991). To standardize the calculations and minimize variability across animals, the magnitudes or slopes of all responses were expressed as percentage of the asymptotic response obtained at control conditions with maximal stimulation $(100 \%)$. The data were analyzed statistically using three-way analysis of variance (ANOVA), with repeated measures; that is, stimulus intensity or interpulse interval (IPI), on one of the variables, followed by Scheffe post-hoc multiple comparisons. Significant level was set at 5\%. In some cases, $t$-tests were used for the comparisons between specific groups.

\section{RESULTS}

\section{Input-Output Relation}

The relationships between stimulation intensity, slope of the EPSP, and magnitude of population spike were similar in controls and TMS-, desipramine- , and mianserin-treated rats ( $n=11,6,5$, and 5, respectively). Both the population EPSPs and the population spikes maintained the same relationship to the stimulation intensity (Figure 1a,b). At stimulus intensities that yielded $50 \%$ of maximal responses the population spikes were for control: $7.0 \pm 0.6 \mathrm{mV}$, TMS: $7.3 \pm 0.8$ $\mathrm{mV}$, mianserin: $6.9 \pm 0.8 \mathrm{mV}$, and desipramine: $6.7 \pm$ $0.9 \mathrm{mV}$. The slopes of the EPSP for the same groups were $2.5 \pm 0.5 \mathrm{~V} / \mathrm{S}, 2.7 \pm 0.55 \mathrm{~V} / \mathrm{S}, 2.3 \pm 0.4 \mathrm{~V} / \mathrm{S}$, and $2.2 \pm$ $0.55 \mathrm{~V} / \mathrm{S}$, respectively.

\section{Paired-Pulse Depression}

Application of the paired-pulse stimulation protocol in control rats caused a suppression of the response to the second stimulus of the pair when their interpulse interval was 15 and $30 \mathrm{~ms}$ (Figure 2). The paired-pulse inhibition was replaced by a nearly $150 \%$ facilitation at 60 $\mathrm{ms}$ interpulse interval.
TMS, desipramine, and mianserin treatments caused a significant reduction in paired-pulse inhibition at 15 and $30 \mathrm{~ms}$ (for $15 \mathrm{~ms}$; ANOVA: $\mathrm{F}=56.65, p<.005$, PS2 / PS1 for 3 volt stimulation: control $=0$, TMS $=0.98 \pm$ 0.15 , desipramine $=1.22 \pm 0.14$, mianserin $=1.02 \pm$ 0.42 ; significant Scheffe comparisons, $p<.05$, were found between the control and each of the treated groups, no difference were found between the different treatments; for $30 \mathrm{~ms}$; ANOVA: $\mathrm{F}=21.59, p<.005$, PS2/ PS1 for 3 volt stimulation: control $=0.20 \pm 0.36$, TMS $=$ $1.66 \pm 0.40$, desipramine $=1.78 \pm 0.35$, mianserin $=$ $1.80 \pm 0.61$; significant Scheffe comparisons $p<.05$, were found between the control and each of the treated groups, no differences were found between the different treatments). The facilitating effect observed in the control at $60 \mathrm{~ms}$ interpulse interval was significantly enhanced by the treatments (Figure 2) (for $60 \mathrm{~ms}$; ANOVA: $\mathrm{F}=10.59, p<.005$, PS2/PS1 for 3-volt stimulation: control $=1.8 \pm 0.43, \mathrm{TMS}=3.38 \pm 0.48$, desipramine $=2.8 \pm$ 0.18 , mianserin $=2.3 \pm 0.58$; significant Scheffe comparison, $p<.05$, were found between the control and TMS- and desipramine-treated groups, but not with mianserin. TMS significantly increased the facilitation compared with mianserin (Scheffe post-hoc test, $p<$ .007) but was not different from desipramine treatment (Scheffe post-hoc test, $p=.285$ ).

\section{Frequency-Dependent Inhibition}

Increasing stimulation frequency from $0.1 \mathrm{~Hz}$ to $1 \mathrm{~Hz}$, at an intensity that evokes $50 \%$ of the maximal asymptotic spike amplitude, caused approximately $50 \%$ reduction of the population spike and EPSP in control rats (Figure 3). Significantly less reduction was found in rats treated with antidepressants (Figure 3) (ANOVA for the PS: $F=40.411, p<.0005$ control $=49 \pm 4.6 \%$ (of $0.1 \mathrm{~Hz}$ values), $\mathrm{TMS}=73 \pm 4.8 \%$, desipramine $=66 \pm$ $4.3 \%$, mianserin $=67 \pm 5.7 \%$; significant Scheffe comparison, $p<.05$, were found between the control and each of the treated groups with no significant difference on Scheffe post-hoc tests between the treatment groups. ANOVA for the EPSP: $\mathrm{F}=34.7, p<.005$ : control $=52 \pm$ $5.3 \%$, TMS $=75 \pm 9.5 \%$, Desipramine $=80 \pm 7.9 \%$, mianserin $=83 \pm 8.7 \%$; significant Scheffe comparisons, $p<.05)$.

\section{Long-Term Potentiation}

In control rats, tetanic stimulation of the perforant path caused a persistent increase in population spike amplitude and EPSP slope. In TMS, desipramine, and mianserin groups, the same stimulation produced significantly greater LTP (Figure 4). (for PS :ANOVA: F = $43.1, p<.005$, control $=42 \% \pm 12.7$, TMS $=115 \pm$ 
A.
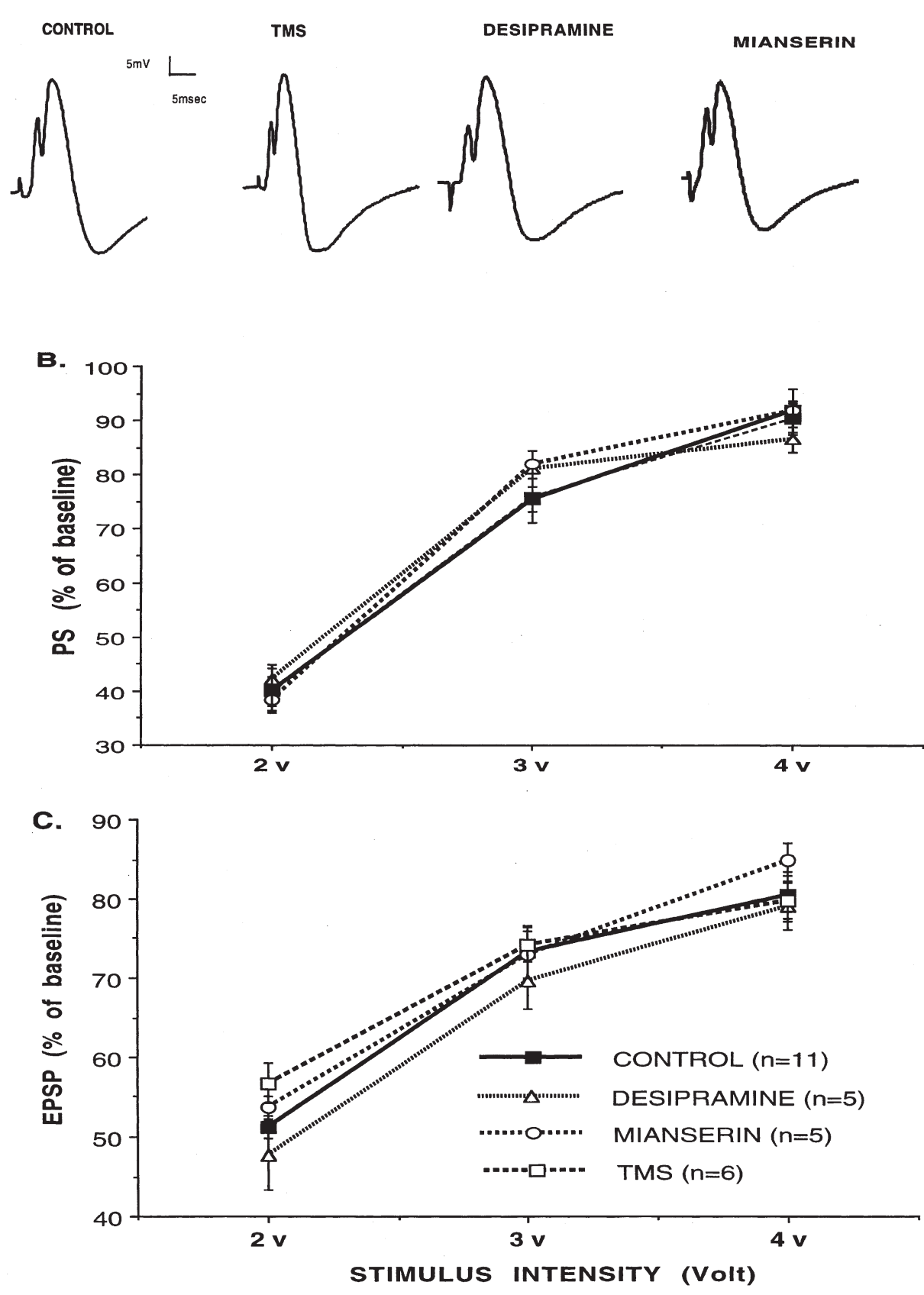

Figure 1. Reactivity to afferent stimulation in control, TMS, desipramine, and mianserin groups. A. Sample illustrations of population responses recorded in the granular layer to stimulation of the perforant path. B\&C Input-output relations, depicting the changes in population spike (B) and EPSP slope $(\mathbf{C})$ as a function of changes in stimulation intensity, are the same in the four groups of rats. Results of $11,6,5$, and 5 rats in each group (respectively).

$28.4 \%$, desipramine $=132 \pm 28.4 \%$, mianserin $=142 \pm$ $25 \%$; significant Scheffe comparisons, $p<.05$, were found between the control and each of the treated groups with no difference on Scheffe post-hoc tests within the treatment groups. ANOVA for the EPSPs: $\mathrm{F}=$ $46.47, p<.05$, : control $=60 \pm 12.4 \%$, TMS $=140 \pm$
$26.9 \%$, desipramine $=114 \pm 24.3 \%$, mianserin $=104 \pm$ $11.4 \%$; significant Scheffe comparison, $p<.05$, were found between the control and each of the treated groups. Significant differences on Scheffe post-hoc tests, $p=.031$ was found between TMS and the mianserin groups). 
A. CONTROL

TMS

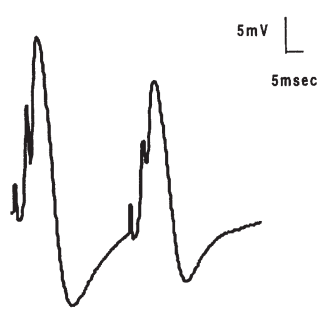

DESIPRAMINE

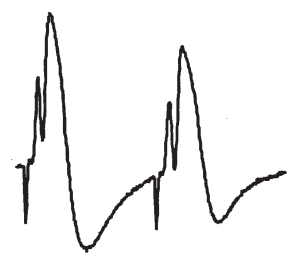

MIANSERIN

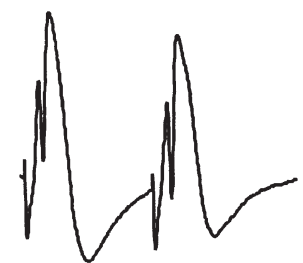

B.

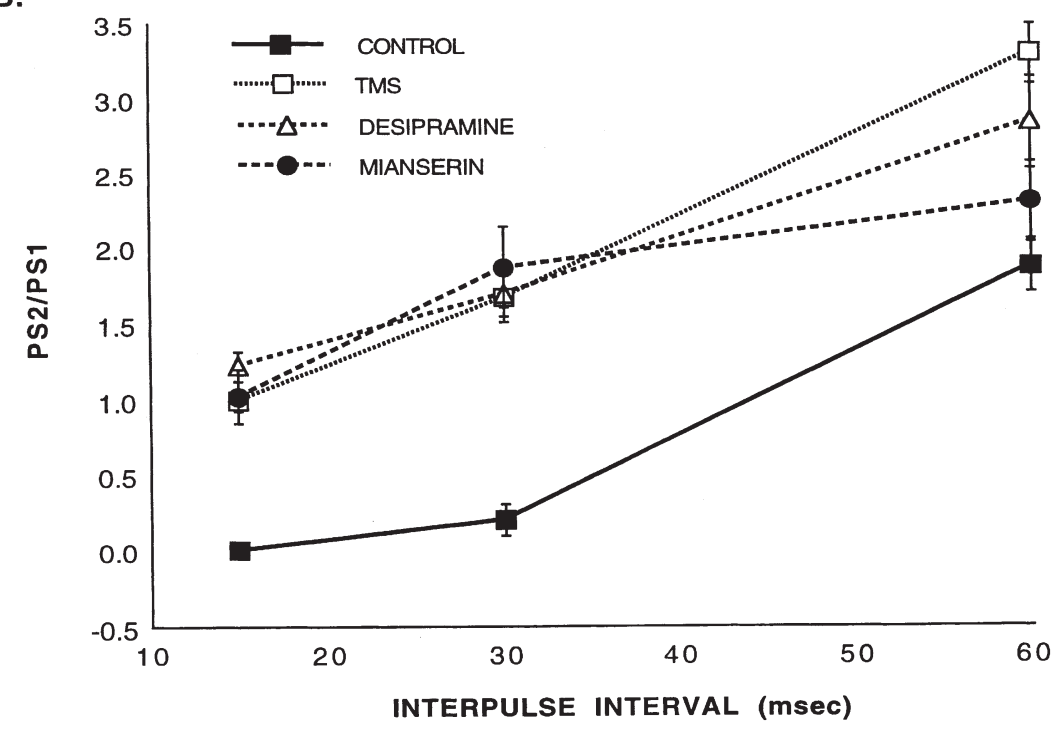

Figure 2. Paired pulse depression is abolished in TMS, desipramine, and mianserin groups. A. Illustrations of paired pulse responses to stimulation applied with a $30 \mathrm{~ms}$ interpulse interval, in control and treated rats. B. Summary of the pairedpulse population spike responses in the four groups.

\section{Serotonergic Modulation}

Fenfluramine (FFA) was applied over an hour after the tetanic stimulation, when most of the potentiated response already dissipated back to control values. In chronic TMS- and mianserin-treated rats, FFA was without effect as compared with the typical $60 \%$ increase in PS seen in control rats (Figure 5). This confirms an earlier observation made with TMS-treated rats (Levkovitz et al. 1999). In contrast, FFA injected to desipramine-treated rats did cause a partial increase in PS (Figure 5). The increase in PS in control and desipramine-treated groups was not accompanied by any change in EPSP slope (ANOVA for PS: $\mathrm{F}=55.2, p<.0005$, : control $50 \% \pm 7.4$, TMS $=-7.5 \% \pm 10.4$, desipramine $=22 \pm 5.7 \%$, mianserin $=1.6 \pm 2.3 \%$; significant Scheffe comparisons, $p<.05$, were found between the control and each of the treated groups with significant difference on Scheffe post-hoc tests between desipramine versus TMS, $p<$ .001 and desipramine versus mianserin, $p<.012$ for EPSP: ANOVA: $\mathrm{F}=0.025, p=.994:$ control $=0 \pm$ $5.08 \%$, TMS $=1.2 \pm 6.3 \%$, desipramine $=5.4 \pm 7.4 \%$, mianserin $=-8.05 \pm 10.4 \%$; no significant Scheffe comparison was found between the groups).

\section{DISCUSSION}

The present study demonstrates a similarity of effects of chronic TMS and two typical antidepressant drugs, mianserin and desipramine, on reactivity of the hippocampus to stimulation of the perforant path, its main excitatory afferent pathway arriving from the entorhinal cortex.

Although these treatments did not affect basal EPSP slopes and population spike size, their effects on pairedpulse and frequency-dependent inhibition indicate that TMS, as do desipramine and mianserin, share a primary action on local inhibitory interneurons activated in these stimulation protocols. In addition, TMS caused a large suppression of the reactivity of the hippocampus to the serotonin-releasing drug FFA, which enhances population spike response to afferent stimulation in the normal 
A.

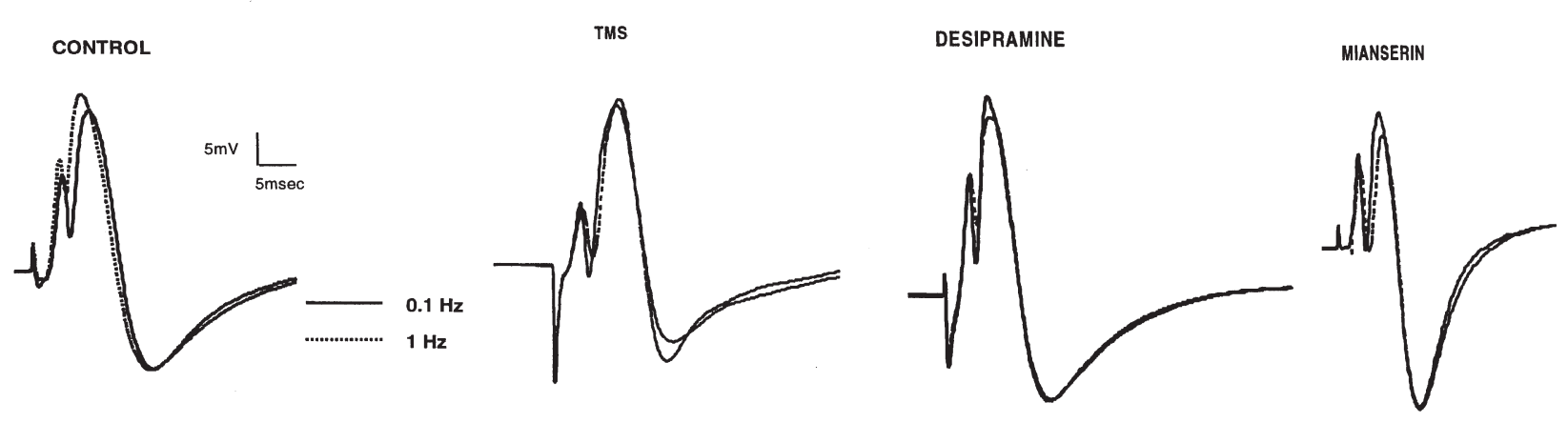

B.

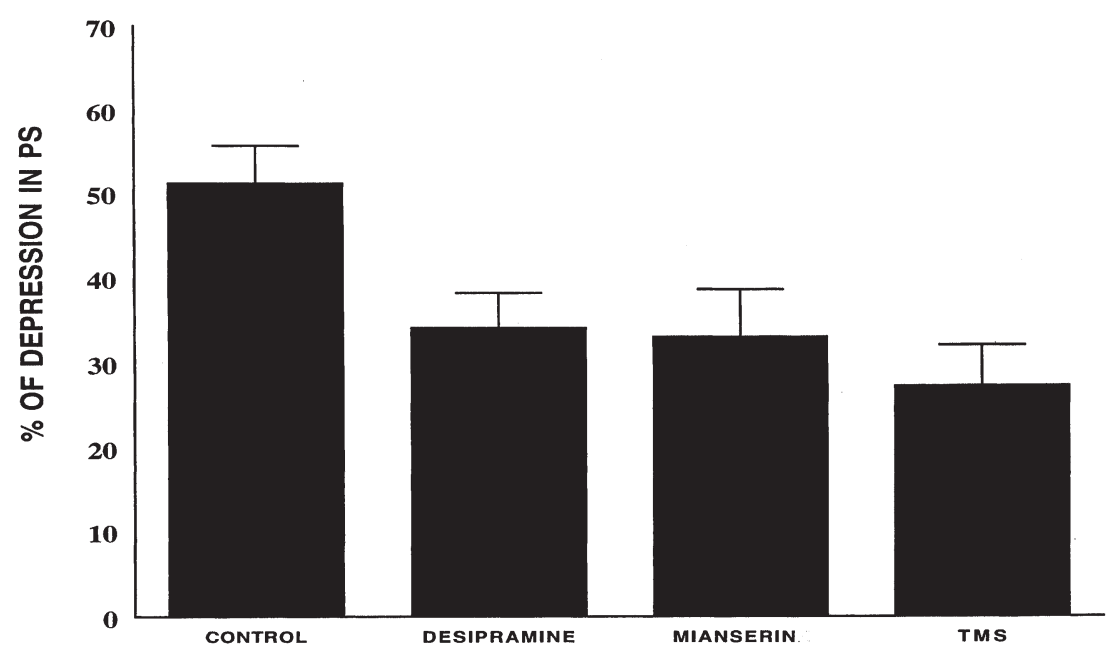

Figure 3. Frequency-dependent inhibition is reduced in TMS, desipramine, and mianserin groups. A. Illustration of frequency response changes in control and treated rats. B. A clear difference between control and treated groups is seen with population spike.

rat brain, as seen before (Levkovitz et al. 1999). Similar suppression was obtained after mianserin treatment. Interestingly, no such effect was seen after chronic treatment with desipramine, which acts primarily at a noradrenergic synapse. This indicates that the effect of mianserin on FFA action is not attributable to a general pharmacological nonspecific action of the chronic drug treatment. Moreover, this disparity indicates that the lack of effect of FFA in TMS or mianserin-treated rats is not attributable to a higher baseline produced by earlier LTP, because this was similar in the desipramine-treated rats. Finally, in an earlier study, (Levkovitz et al. 1999) FFA was ineffective in TMS-treated rats, and it was tested without prior LTP protocol.

Suppression of paired-pulse inhibition should cause an increase in excitability. This enhanced excitability may contribute to the increased LTP seen in all three experimental groups. A relationship between excitability and ability to express LTP has been seen before (see Levkovitz et al. 1999, and references therein). Thus, tetanic stimulation normally causes a large depolariza- tion, and consequent activation of GABAergic neurons, which will clamp the membrane near $\mathrm{Cl}^{-}$potential and prevent further depolarization. Blockade of this inhibitory tone will allow this extra depolarization so that a massive influx of calcium into the postsynaptic cells will facilitate a larger LTP expression.

Reduced efficacy of FFA may either mean that serotonin is not being released or that it is not as effective at the postsynaptic site, perhaps because of receptor subsensitivity. In an earlier study, we proposed, at least for TMS, that the former possibility is more likely, because direct application of serotonin into the hippocampus of TMS-treated rats could still enhance population spikes, as FFA or serotonin do in control rats (see Levkovitz et al. 1999) (for technical reasons, we could not test it in the present study for mianserin, so it is still an open question with respect to this drug). Either way, reduced efficacy of FFA means that less serotonin is being released by the drug. These results are intuitively similar to studies reporting both excitatory and inhibitory effects of TMS (Wang and Scheich 1996). Interestingly, 

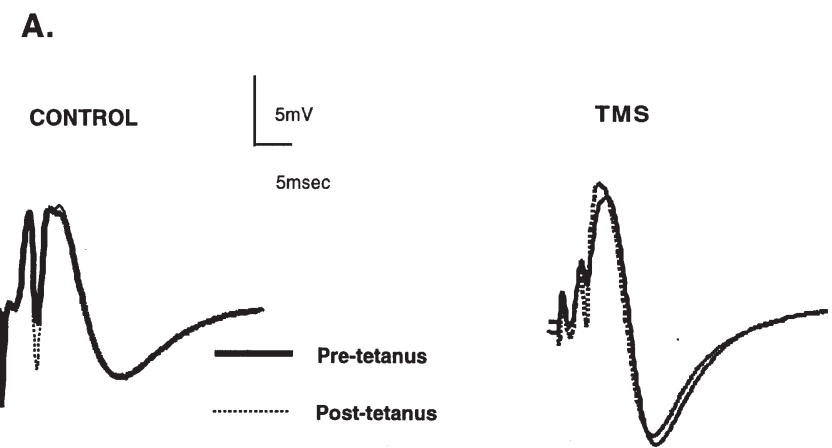

DESIPRAMINE
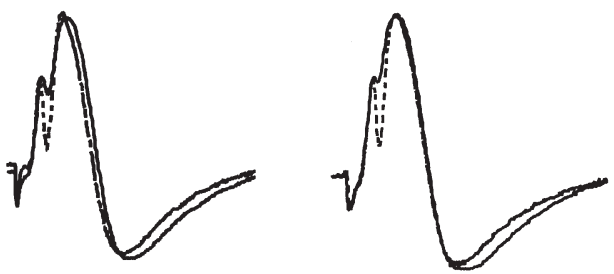

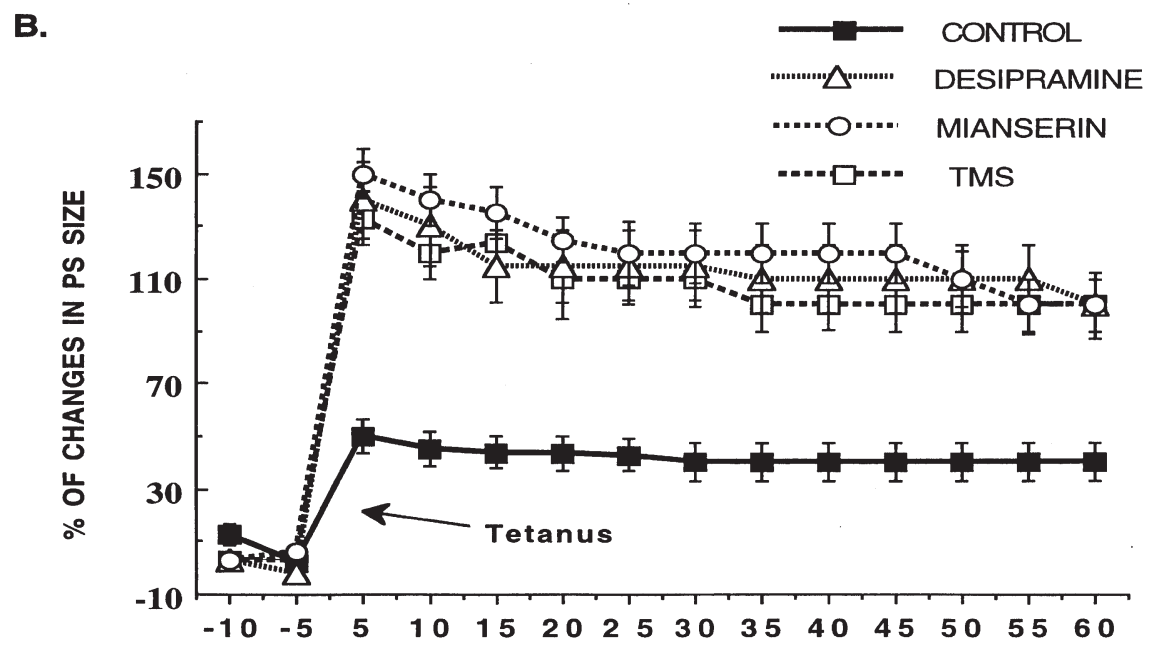

Figure 4. LTP is enhanced in treated rats. A. Sample illustration of evoked responses before and after tetanic stimulation producing LTP in control and treated rats. B. Tetanic stimulation is applied the arrowhead and a significant difference, between control and antidepressant treated rats is in population spike.

one of the well-known adverse effects of the tricyclic antidepressants is to reduce the seizure threshold, while becoming sedative on the other hand (Kessel and Simpson 1995).

Although our normal rats cannot constitute a genuine model system for affective disorders in humans, especially because there are known differences in the efficacy of antidepressive drugs between normal and depressed patients, our results can propose a mechanism of action of TMS as an antidepressant. The fact that these treatments share an effect on some elementary cellular mechanisms related to inhibitory processes makes it likely that these are also affected in the depressed brain.

A major impairment in depressive disorder involves memory functions that improve with different antidepressive treatments (Burt et al. 1995). LTP is considered a model mechanism for learning and memory in animals (Laroche 1985). We demonstrated here for the first time in the intact brain that either TMS or tricyclic antidepressants enhance LTP above the potentiation that is produced normally. In previous studies, a reduc- tion in LTP following selective depletion of monoamines was found in the dentate gyrus of the rat hippocampus (Bliss et al. 1983). This indicates that the antidepressants may exert their effects by enhancing serotonin neurotransmission.

Enhancement of 5-HT transmission seems to be a common outcome of antidepressant treatment (Haddjeri et al. 1998). Even the selective norepinephrine reuptake blocker, desipramine, had been shown to cause changes in serotonin release in the rat hippocampus after chronic treatment (Yoshioka et al. 1995). Various classes of antidepressant treatments enhance 5-HT neurotransmission with a time course consistent with their delayed therapeutic activity. Clinical evidence in support of the involvement of 5-HT is provided by the antidepressant activity of the selective serotonin reuptake blockers. In addition, the reduction in 5-HT levels, induced by either p-chlorophenylalanine (a 5-HT synthesis inhibitor) or the dietary depletion of the 5-HT precursor l-tryptophan, reverses the antidepressant effect of several drugs (Shopsin et al. 1975; Delgado et al. 1990). Preclinical evidence suggests that long-term antidepressant treatments enhance 

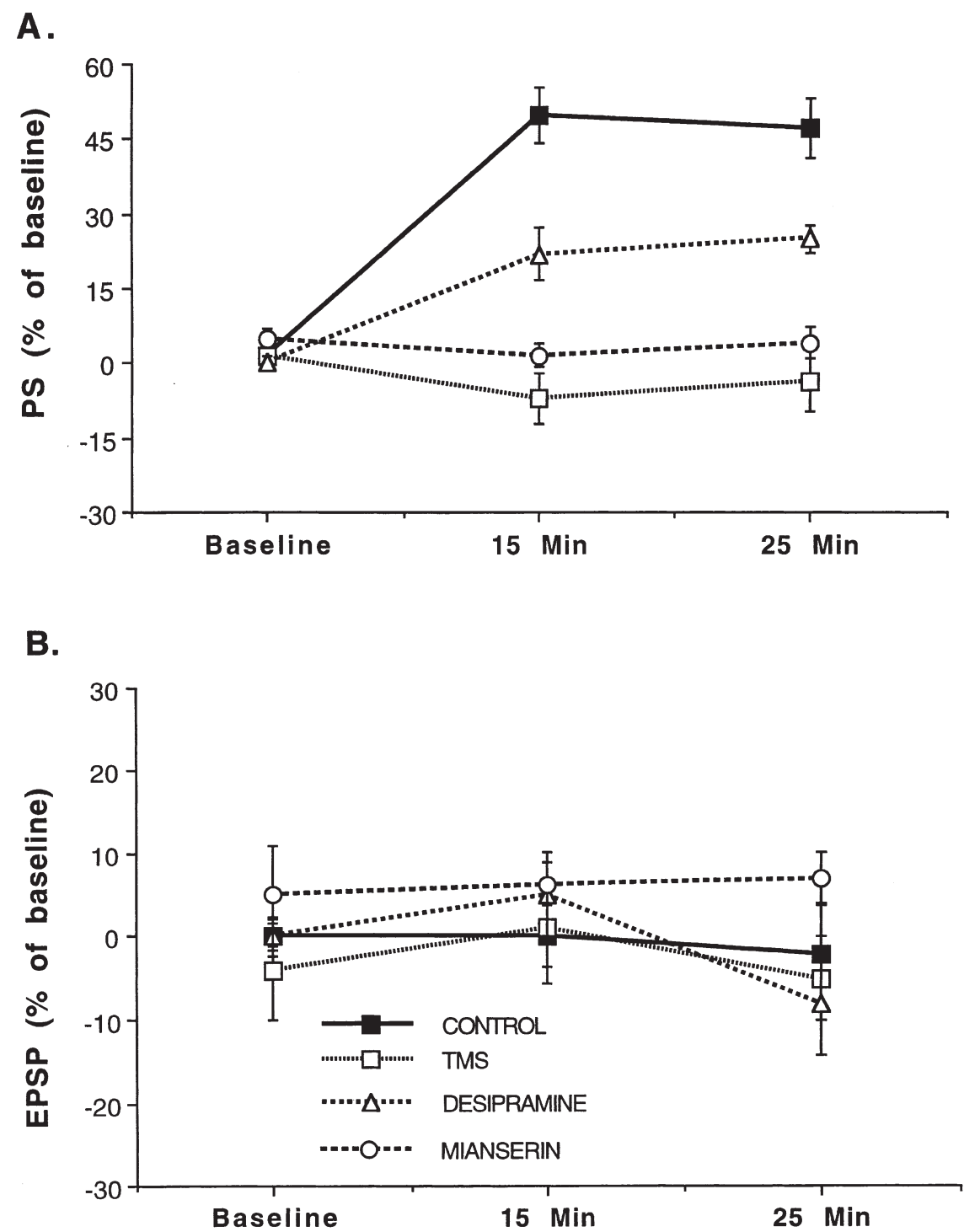

Figure 5. (A) FFA applied intraperitoneally produced a typical increase in population spike in control rats, partial increase in desipramine-treated rats and it does not affect responses in the TMS- and mianserin-treated rats. (B) There was no difference between control and the treated groups in the slopes of the EPSPs.

5-HT neurotransmission via different adaptive changes (Blier and deMontigny 1994) and this enhancement of 5-HT neurotransmission seems to be common to all antidepressant treatments (Haddjeri et al. 1998).

Our results on the reduction in efficacy of FFA can be reconciled with the suggested increase in serotonergic neurotransmission following chronic antidepressant treatment (Blier and deMontigny 1994). If, indeed, the chronic treatment causes a continuous release of serotonin and/or an increase in receptor sensitivity, we can expect that the added release, evoked by FFA, will not be effective. Moreover, the chronic increase in serotonin release can have an indirect, downregulating action on the receptor for FFA. Finally, the effects of the antidepressants to increase excitability of the hippocampus are consistent with this possibility. A more direct test to this hypothesis awaits further experiments.

With growing evidence of hippocampus atrophy in depression, its linkage to memory impairment (Sheline et al. 1999) and treatment effects on hippocampal neuronal morphology (Vaidya et al. 1999) it is evident that the hippocampus became an important target for the study of new antidepressant effects in the brain. Thus, even if TMS may not target the hippocampus in the human brain, because of its physical location deep in the temporal lobe, an indirect action of TMS on frontal cortex may cause an enhanced release of serotonin in the hippocampus (Juckel et al. 1999), and a subsequent improvement in cognitive and emotional functions associated with the hippocampus. 


\section{ACKNOWLEDGMENTS}

Supported by a grant from The National Center for Psychobiology in Israel, by the Kass foundation and the Abramson Family Foundation.

\section{REFERENCES}

Barker AT (1991): An introduction to the basic principles of magnetic nerve stimulation. J Clin Neurophysiol 8:26-37

Barker AT, Freeston IL, Jalinous R, Jarratt JA (1986): Clinical evaluation of conduction time measurements in central motor pathway using magnetic stimulation of human brain. Lancet 1:1325-1326

Blier P, deMontigny C (1994): Current advances and trends in the treatment of depression. Trends Pharmacol Sci $15: 220-226$

Bliss TV, Goddard GV, Rlives M (1983): Reduction of longterm potentiation in the dentate gyrus of the rat following selective depletion of monoamines. J Physiol 334:475-491

Burt DB, Zembar MJ, Niederehe G (1995): Depression and memory impairment: A meta analysis of the association, its pattern, and specificity. Psychol Bull 117:285-305

Cohen LG, Roth BJ, Nilsson J, Dang N, Panizza M, Bandinelli S, Friauf W, Hallett M (1990): Effects of coil design on delivery of focal magnetic stimulation. Electroencephal Clin Neurophysiol ;75:350-357

Delgado PL, Miller MLL, Solomon RM, Van Vilthoven V, Heninger GR, Charney DS (1990): Serotonin function and the mechanism of antidepressant action : Reversal of antidepressant-induced remission by rapid depletion of plasma tryptophan. Arch Gen Psychiat 47:411-418

Gates JR (1995): Transcranial magnetic stimulation. Neuroimaging Clin N Am 5:711-720

George MS, Wasermann EM, Williams WA, Callahan A, Ketter TA, Basser P, Hallett M, Post RM (1995): Daily repetitive transcranial magnetic stimulation improves in refractory depression. Neuroreport 6:1853-1856

Grisaru N, Yaroslavsky U, Abarbanel J, Lamberg T, Belmaker RH (1994): Transcranial magnetic stimulation in depression and schizophrenia. Eur Neuropsychopharmacol 4:287-288

Haddjeri N, Blier P, Montigny C (1998): Long-term antidepressant treatments result in a tonic activation of forebrain 5-HT1A receptors. J Neurosci 18:10150-10156

Hallett M, Cohen LG (1989): Magnetism: A new method for stimulation of nerve and brain. JAMA 262:538-541

Hoflich G, Kasper S, Hunfnagel A, Ruhrmann S, Moller HJ (1993): Application of transcranial magnetic stimulation in treatment of drug resistance major depressionReport of two cases. Hum Psychopharmacol 8:361-365

Juckel G, Mendlin A, Jacobs BL (1999): Electrical stimulation of rat medial prefrontal cortex enhances forebrain serotonin output: Implications for electroconvulsive therapy and transcranial magnetic stimulation in depression. Neuropsychopharmacology 21:391-398
Kessel JB, Simpson GM (1995): Tricyclic and tetracyclic drugs. In Kaplan HI and Sadock BJ (eds), Comprehensive Textbook of Psychiatry. Williams \& Wilkins, Baltimore, p 2096.

Klein E, Kreinin I, Chistyakov A, Koren D, Mercz L, Marmur S, Ben-Shachar D, Feinsod M (1999): Therapeutic efficacy of right prefrontal slow repetitive treanscranial magnetic stimulation in major depression: A doubleblind controlled study. Arch Gen Psychiat 56:315-320

Krishnan KR, Doraiswamy PM, Figiel GS, Husian MM, Shah SA, Na C, Boyko OB, McDonald WM, Nemeroff CB, Ellinwood EH Jr (1991): Hippocampal abnormalities in depression. J Neuropsychiat Clin Neurosci 3:387-391

Laroche S (1985): What can the long-term potentiation procedure tell us about the neural mechanisms of learning and memory? In Will BE, Schmitt P, Dalrymple-Alford JC (eds), Advances in Behavioral Biology, vol. 28, Brain Plasticity, Learning, and Memory. New York, Plenum, pp 139-155

Levkovitz Y and Segal M (1997): Serotonin 5-HT1A receptors modulate hippocampal reactivity to afferent stimulation. J Neurosci 17:5591-5598

Levkovitz Y, Marx J, Grisaru N, Segal M (1999): Long-term effects of transcranial magnetic stimulation on hippocampal reactivity to afferent stimulation. J Neurosci 19:3198-3202

Richter-Levin, G. and Segal M (1991): The effects of serotonin depletion and raphe grafts on hippocampal electrophysiology and behavior. J Neurosci 11:1585-1596

Shah PJ, Embeier KP, Glabus MF, Goodwin GM (1998): Cortical gray matter reductions associated with treatmentresistant chronic unipolar depression. Controlled magnetic resonance imaging study. Br J Psychiat 172:527-532

Sheline YI (1996): Hippocampal atrophy in major depression: A result of depression-induced neurotoxicity? Mol Psychiat 4:298-299

Sheline YI, Wang PW, Gado MH, Csernansky JG, Vannier MW (1996): Hippocampal atrophy in recurrent depression 93:3908-3913

Sheline YI, Sanghavi M, Mintun MA, Gado MH (1999): Depression duration but not age predicts hippocampal volume loss in medically healthy woman with recurrent major depression. J Neurosci 19:5034-5043

Shopsin B, Gershon S, Golstein M (1975): The use of synthesis inhibitors in defining a role for biogenic amines during imipramine treatment in depressed patients. Psychopharmacol Com 1:239-249

Vaidya VA, Suiciak JA, Du F, Duman RS (1999): Hippocampal mossy fiber spouting induced by chronic electroconvulsive seizures. Neuroscience 89:157-166

Yoshioka M, Matsumoto M, Numazawa R, Togashi H, Smith CB, Saito H (1995): Changes in the regulation of 5 -HT release by alpha 2-adrenoreceptors in the rat hippocampus after long-term desipramine treatment. Eur J Pharmacol 294:565-570

Wang H, Scheich H (1996): LTD and LTP induced by transcranial magnetic stimulation in auditory cortex. NeuroReport 7:521-525 